\title{
Hubungan Faktor Lingkungan dengan Penggunaan Trihexyphenidyl pada Remaja di BNN Kota Surabaya
}

\author{
Indri Riza Priescisila, Mahmudah \\ Departemen Biostatistika dan Kependudukan \\ FKM Universitas Airlangga Jl. Mulyorejo Kampus C UNAIR 60115 \\ Alamat Korespondensi: \\ Indri Riza Priescisila \\ Indri.prisila@yahoo.com
}

\begin{abstract}
Drugs abuse is increase every years. One of the type of medicines that often abused by teenager is trihexyphenidyl or commonly called pills koplo. The use of a drug was influenced some of factors, such as environment (schools, family, and their peers). The purpose of this research to find out the relationship between environment factors with the use of trihexyphenidyl by teenager in BNN Surabaya City. The research was observational research by design cross sectional. Technique sampling the research is simple random sampling, from teenager was 12-21 years and used trihexyphenidyl who performs outpatient in BNN Surabaya City as many as 48 people. The research was done at September 2015-Januari 2016 in BNN Surabaya city. The results showed that 52,1 percent teenager was 12-15 years old and male (66.7 percent). Half of teenager had completed their junior high school of 62.5 percent and the parents of teenagers work as a private employees. The most teenagers 54,2 percent used trihexyphenidyl among 1-3 years. Teenager stop using trihexyphenidyl were 62.5 percent. The results of the chi square analysis showed that there was no correlation between schools, family, and their peers variables with the use of trihexyphenidyl by teenager in BNN Surabaya City. The usage of trihexyphenidyl among teenager not only caused by several factors individual and their peers factors, but there are still many other reasons. The program intervention required to address the problems is providing information about danger of drugs usage or abuse medicines to teenager or the Surabaya community.
\end{abstract}

Keywords: drugs abuse, teenager, trihexyphenidyl

\begin{abstract}
ABSTRAK
Penggunaan obat berbahaya setiap tahunnya cenderung meningkat. Salah satu jenis obat yang sering disalahgunakan remaja adalah trihexyphenidyl atau yang disebut pil koplo. Penggunaan obat tersebut dipengaruhi oleh beberapa faktor. Faktor tersebut adalah faktor lingkungan yang terdiri dari lingkungan sekolah, keluarga, dan teman sebaya. Tujuan dari penelitian ini adalah untuk mengetahui hubungan antara faktor lingkungan dengan penggunaan trihexyphenidyl pada remaja di BNN Kota Surabaya. Penelitian ini merupakan penelitian observasional dengan desain cross sectional. Teknik sampling pada penelitian ini adalah simple random sampling dengan sampel remaja pengguna trihexyphenidyl berusia 12-21 tahun yang melakukan rawat jalan di BNN Kota Surabaya sebanyak 48 orang. Penelitian ini dilakukan pada bulan September 2015-Januari 2016 di BNN Kota Surabaya. Hasil penelitian menunjukkan bahwa sebesar 52,1 persen remaja berusia 12-15 tahun dan berjenis kelamin laki-laki (66,7 persen). Separuh dari remaja berpendidikan SMP dan 62,5 persen orang tua remaja bekerja sebagai pegawai swasta. Sebesar 54,2 persen remaja menggunakan trihexyphenidyl dalam rentang waktu 1-3 tahun. Saat ini remaja yang telah berhenti menggunakan trihexyphenidyl berjumlah 62,5 persen. Hasil analisis menunjukkan tidak ada hubungan antara faktor lingkungan sekolah, keluarga, dan teman sebaya dengan penggunaan trihexyphenidyl pada remaja di BNN Kota Surabaya. Penyebab dari penggunaan trihexypehenidyl pada remaja tidak hanya disebabkan oleh faktor lingkungan saja, namun masih banyak penyebab lainnya. Penyuluhan tentang bahaya dan dampak penggunaan narkoba atau penyalahgunaan obat sangat diperlukan oleh remaja atau masyarakat di wilayah Surabaya.
\end{abstract}

Kata kunci: Penyalahgunaan Obat, remaja, trihexyphenidyl

\section{PENDAHULUAN}

Penggunaan narkoba saat ini sudah menjadi masalah di negara-negara berkembang dan negara maju. Peredaran narkoba kini sudah menyebar di kalangan masyarakat. Tidak hanya di kota besar, wilayah pedesaan juga menjadi sasaran penyebarluasan narkoba (Martono, 2008). 
Istilah narkoba sudah tidak asing bagi masyarakat. Dalam bahasa kedokteran narkoba sering juga disebut dengan Napza (Narkotika, Psikotropika, dan Zat Adiktif lainnya). Pada intinya narkoba ataupun napza merupakan bahan atau zat yang jika digunakan dapat mempengaruhi kerja otak (Amriel, 2007).

Remaja merupakan golongan rentan untuk melakukan penyalahgunaan narkoba. Hal ini disebabkan oleh sifat remaja yang dinamis, selalu ingin coba-coba, mudah putus asa dan mudah terpengaruh sehingga mudah terjerat pada perilaku menyimpang (Razak dan Sayuti, 2006).

Remaja merupakan masa peralihan dari anak-anak menjadi dewasa. Hurlock (1968) mendefinisikan usia remaja dimulai pada usia 12-21 tahun. Pada masa ini remaja akan mencari pola hidup yang sesuai dengan dirinya. Biasanya remaja akan melakukan aksi coba-coba untuk menentukan pola hidup yang nyaman untuk remaja (Chomaria, 2008).

Pada masa remaja terjadi beberapa perubahan perilaku akibat tuntutan lingkungan sekitar. Lingkungan sekitar mengharapkan remaja untuk bertanggung jawab seperti orang dewasa. Perubahan tersebut dapat membuat remaja bingung untuk menentukan identitasnya. Akibatnya remaja akan menghadapi masalahmasalah dengan orang tua, teman, ataupun sekolahnya (Willis, 2015).

Penyalahgunaan narkoba pada remaja berawal dari penawaran pengedar narkoba sehingga remaja mulai merasakan efek obat tersebut dan merasa ketagihan. Tidak jarang pengedar narkoba juga menganjurkan remaja untuk menyebarluaskan obat tersebut (Gunawan, 2006).

Badan Narkotika Nasional (BNN) Kota Surabaya telah bekerja sama dengan Pusat Penelitian Kesehatan Universitas Indonesia (Puslitkes UI) dalam Survei Perkembangan Penyalahgunaan Narkoba tahun 2014. Berdasarkan survei tersebut didapat bahwa jumlah pengguna narkoba di Indonesia pada tahun 2008 telah mencapai 3,8 juta orang. Kemudian terjadi peningkatan di tahun 2011 yaitu sebesar 4,2 juta orang dan di tahun 2015 mencapai 5 juta orang. Tahun 2014 telah tercatat sebesar 27,32 persen pengguna narkoba adalah pelajar. Meskipun angka tersebut relatif kecil, namun dampak dari penggunaan narkoba di kalangan remaja sangatlah besar seperti rusaknya syaraf pada tubuh, kecanduan hingga terjadi over dosis sampai kematian.

Data rekapitulasi BNN Kota Surabaya juga menunjukkan dari bulan Januari hingga Agustus 2015 terdapat 282 orang menjadi pengguna narkoba dengan pengguna trihexyphenidyl sebesar 54,0 persen. Pengguna sabu sebesar 16,3 persen, ganja 11,7 persen dan narkoba jenis lain sebesar 18 persen. Selain itu data tersebut juga menginformasikan bahwa usia pengguna narkoba yang berusia 10-20 tahun sebanyak 41,5 persen adalah pelajar.

Pengguna narkoba sebesar 13 persen telah dirujuk ke beberapa instansi pemerintah dan swasta untuk melakukan rawat inap. Sedangkan 64,2 persen lainnya melakukan rawat jalan di Puskesmas Dupak Surabaya dan 34,3 persen melakukan konseling di BNN Kota Surabaya.

Dampak penggunaan narkoba tidak hanya terjadi pada fisik pengguna narkoba. Jika narkoba tidak segera ditanggulangi maka akan merusak hubungan kekeluargaan, menurunkan kemampuan belajar, menurunkan produktivitas kerja, dan meningkatkan angka kriminalitas.

Jenis narkoba yang paling banyak digunakan adalah jenis ganja, sabu, dan ekstasi. Tidak hanya jenis itu saja, jenis pil koplo juga banyak dikonsumsi oleh kalangan pelajar karena harganya yang murah dan dapat dijangkau oleh kalangan pelajar. Selain itu efek mabuk atau $f y$ juga membuat remaja memilih menggunakan trihexyphenidyl. Namun, untuk mendapatkan efek tersebut dengan cara menambahkan dosis melebihi anjuran yang disarankan atau yang disebut dengan penyalahgunaan obat (Amriel, 2007).

Penyalahgunaan obat merupakan keadaan obat tersebut digunakan tidak sesuai anjuran. Hal ini dapat mengakibatkan toleransi bagi tubuh yang artinya dosis yang dibutuhkan akan semakin besar untuk mendapat efek yang diinginkan. Tidak sedikit remaja yang menggunakan trihexyphenidyl telah mengalami toleransi obat, sehingga mengalami overdosis (Amriel, 2007).

Trihexyphenidyl merupakan obat keras yang sering digunakan oleh dokter untuk mengobati parkinson dan juga sebagai obat penenang pada 
pasien gangguan jiwa. Jadi penggunaan obat tersebut haruslah dengan resep dokter.

Efek dari penggunaan trihexyphenidyl adalah detak jantung meningkat, pusing, penglihatan kabur, mual, muntah, diare, depresi dan kebingungan. Remaja gemar menggunakan obat ini selain harganya yang murah, obat ini membuat efek mabuk dan tenang sesaat (Kemienski, Mery dan James, 2006).

Cara yang bersifat preventif dan representatif diperlukan untuk meminimalkan penyalahgunaan obat berbahaya. Secara preventif adalah dengan mengubah pola pikir masyarakat atau membangun kesadaran bahwa penggunaan narkoba sangat berbahaya untuk kelangsungan hidup. Sedangkan secara represif adalah pecandu atau mantan pengguna narkoba dapat menata hidup kembali tanpa berhubungan dengan obat tersebut (Martono, 2008)

Najmudin (2007), mengemukakan bahwa faktor lingkungan dapat mempengaruhi remaja menggunakan narkoba. Faktor tersebut meliputi lingkungan keluarga, lingkungan sekolah dan lingkungan teman sebaya.

Tujuan dari penelitian ini adalah menganalisis hubungan faktor lingkungan (sekolah, keluarga, teman sebaya) dengan penggunaan trihexyphenidyl pada remaja di BNN Kota Surabaya.

\section{METODE PENELITIAN}

Penelitian ini adalah penelitian analitik yang bertujuan untuk menganalisis hubungan faktor individu dan teman sebaya dengan penggunaan trihexyphenidyl pada remaja. Desain dari penelitian adalah cross sectional yaitu subjek penelitian di observasi hanya satu saat saja. Penelitian dilakukan di BNN Kota Surabaya pada bulan September 2015-Januari 2016, dengan alasan BNN Kota Surabaya merupakan lembaga yang bertugas untuk melakukan penyidikan dan penyelidikan kasus narkoba di wilayah Surabaya. Seluruh kasus narkoba di wilayah Surabaya akan dibawa ke BNN Kota Surabaya untuk diproses lebih lanjut.

Populasi dalam penelitian ini adalah seluruh remaja pengguna trihexyphenidyl dengan usia
12-21 tahun yang melakukan rawat jalan di BNN Kota Surabaya pada bulan Oktober-Nopember 2015 dan jumlah sampel sebanyak 48 orang.

Variabel independen dalam penelitian ini adalah faktor lingkungan yang meliputi lingkungan sekolah, keluarga dan teman sebaya. Faktor lingkungan sekolah dapat dilihat dari penerapan disiplin beserta tanggung jawab dalam keluarga, kontrol keluarga, dan keutuhan keluarga. Kemudian faktor lingkungan sekolah dapat dilihat dari kedisiplinan sekolah, letak sekolah yang dekat dengan tempat hiburan, dan terdapat pengguna narkoba dalam lingkungan sekolah. Sedangkan untuk faktor teman sebaya dapat dilihat melalui frekuensi pertemuan dengan teman sebaya, tawaran narkoba dari teman, dan ancaman dari teman sebaya.

Pengumpulan data dilakukan dengan menggunakan data primer dan data sekunder. Pada data primer digunakan kuesioner yang berisikan karakteristik responden dan beberapa pertanyaan tentang faktor lingkungan (lingkungan keluarga, sekolah dan teman sebaya) yang menyebabkan remaja mengunakan trihexyphenidyl. Sedangkan data sekunder diambil dari rekam medis responden untuk mengetahui lama penggunaan trihexyphenidyl dan status penggunaan responden pada saat ini.

Analisis data dilakukan dengan cara deskriptif dan analitik. Secara deskriptif dilakukan penyajian distribusi frekuensi dalam bentuk angka dan persentase mengenai karakteristik responden (usia, jenis kelamin, pendidikan, pekerjaan orang tua, lama penggunaan, status penggunaan saat ini). Sedangkan untuk mengetahui hubungan antara faktor lingkungan (keluarga, sekolah, teman sebaya) dengan penggunaan trihexyphenidyl pada remaja digunakan analisis chi square.

\section{HASIL PENELITIAN}

Hasil pada penelitian ini meliputi karakteristik responden (usia, jenis kelamin, lama penggunaan, status penggunaan saat ini) dan analisis hubungan antara faktor lingkungan dengan penggunaan trihexyphenidyl pada remaja. 
Usia

Usia responden rata-rata berumur 15,48 tahun dengan nilai tengah 14,50 tahun. Paling banyak responden berusia 13 tahun. Umur terendah responden adalah 12 tahun dan umur tertinggi responden adalah 20 tahun.

Remaja yang menggunakan trihexyphenidyl sebesar 52,1 persen berusia 12-15 tahun. Sedangkan yang berusia 16-18 tahun tidak mempunyai selisih yang besar dengan yang berusia 19-21 tahun. Usia responden secara rinci dapat dilihat pada Tabel 1.

\section{Jenis Kelamin}

Hasil penelitian menunjukkan bahwa sebesar 66,7 persen responden berjenis kelamin laki-laki. Secara lebih rinci dapat dilihat pada Tabel 2.

\section{Pendidikan}

Pendidikan pada penelitian ini meliputi jenis pendidikan yang saat ini ditempuh oleh responden. Hasil penelitian menunjukkan bahwa dari 48 responden separuhnya adalah berpendidikan SMP. Sedangkan yang berpendidikan SMA tidak jauh berbeda dengan pendidikan SMP yaitu 31,3 persen. Pendidikan

Tabel 1. Gambaran Pengguna Trihexyphenidyl berdasarkan Usia Pada Bulan Oktober-Nopember 2015 di BNN Kota Surabaya

\begin{tabular}{lcc}
\hline Usia & Frekuensi & Persentase(\%) \\
\hline 12-15 tahun & 25 & 52,1 \\
16-18 tahun & 11 & 22,9 \\
19-21 tahun & 12 & 25,0 \\
\hline Total & $\mathbf{4 8}$ & $\mathbf{1 0 0}$ \\
\hline
\end{tabular}

Tabel 2. Gambaran Pengguna Trihexyphenidyl berdasarkan Jenis Kelamin Bulan Oktober-Nopember 2015 di BNN Kota Surabaya

\begin{tabular}{lcc}
\hline Jenis Kelamin & Frekuensi & Persentase(\%) \\
\hline Laki-laki & 32 & 66,7 \\
Perempuan & 16 & 33,3 \\
\hline Total & $\mathbf{4 8}$ & $\mathbf{1 0 0}$ \\
\hline
\end{tabular}

pengguna trihexyphenidyl di BNN Kota Surabaya dapat dilihat lebih rinci pada Tabel 3.

\section{Pekerjaan Orang Tua}

Berdasarkan penelitian yang dilakukan pada remaja di BNN Kota Surabaya didapat hasil bahwa paling banyak jenis pekerjaan orang tua responden adalah sebagai swasta. Secara rinci jenis pekerjaan orang tua responden dapat dilihat pada Tabel 4.

\section{Lama Penggunaan}

Lama penggunaan trihexyphenidyl oleh responden dapat dilihat dari perhitungan waktu pertama kali penggunaan trihexyphenidyl hingga saat ini. Pada lama penggunaan trihexyphenidyl didapat hasil bahwa rata-rata responden menggunakan trihexyphenidyl selama 16,4 bulan dengan nilai median 12 bulan. Penggunaan trihexyphenidyl paling banyak adalah selama 14 bulan. Penggunaan paling cepat selama 5 bulan dan paling lama selama 48 bulan.

Lama penggunaan trihexyphenidyl oleh responden paling banyak yaitu sebesar 54,2 persen berada dalam rentang waktu 1-3 tahun.

Tabel 3. Gambaran Pengguna Trihexyphenidyl Pada Remaja Menurut Pendidikan di BNN Kota Surabaya

\begin{tabular}{lcc}
\hline Pendidikan & Frekuensi & Persentase(\%) \\
\hline SMP & 24 & 50,0 \\
SMA & 19 & 31,3 \\
PT & 7 & 18,8 \\
\hline Total & $\mathbf{4 8}$ & $\mathbf{1 0 0}$ \\
\hline
\end{tabular}

Tabel 4. Gambaran Pengguna Trihexyphenidyl pada Remaja berdasarkan Jenis Pekerjaan Orang Tua di BNN Kota Surabaya

\begin{tabular}{lcc}
\hline Pekerjaan & Frekuensi & Persentase(\%) \\
\hline PNS & 7 & 14,6 \\
Swasta & 30 & 62,5 \\
Wiraswasta & 11 & 22,9 \\
\hline Total & $\mathbf{4 8}$ & $\mathbf{1 0 0}$ \\
\hline
\end{tabular}


Tabel 5. Gambaran Pengguna Trihexyphenidyl pada Remaja berdasarkan Lama Penggunaan pada Bulan OktoberNopember 2015 di BNN Kota Surabaya

\begin{tabular}{lcc}
\hline $\begin{array}{l}\text { Lama } \\
\text { Penggunaan }\end{array}$ & Frekuensi & Persentase(\%) \\
\hline$<1$ tahun & 18 & 37,5 \\
$1-3$ tahun & 26 & 54,2 \\
$>3$ tahun & 4 & 8,3 \\
\hline Total & $\mathbf{4 8}$ & $\mathbf{1 0 0}$ \\
\hline
\end{tabular}

Lama penggunaan trihexyphenidyl pada remaja secara rinci dapat dilihat pada Tabel 5.

\section{Status Penggunaan Trihexyphenidyl Saat Ini}

Status penggunaan trihexyphenidyl saat ini merupakan kondisi responden saat melakukan rawat jalan terkait penggunaan trihexyphenidyl. Status penggunaan tersebut meliputi apakah responden masih menggunakan atau sudah berhenti menggunakan trihexyphenidyl dalam satu bulan terakhir.

Hasil penelitian menunjukkan bahwa sebesar 62,5 persen responden telah berhenti menggunakan trihexyphenidyl. Secara lengkap dapat dilihat pada Tabel 6 .

\section{Faktor Lingkungan Keluarga}

Pada faktor lingkungan keluarga diukur dengan menggunakan beberapa pertanyaan tentang sebab yang timbul dari diri responden terkait penggunaan trihexyphenidyl. Gambaran
Tabel 6. Gambaran Pengguna Trihexyphenidyl pada Remaja menurut Status Penggunaan Saat ini

\begin{tabular}{lcc}
\hline Status & Frekuensi & Persentase(\%) \\
\hline $\begin{array}{l}\text { Masih } \\
\text { menggunakan }\end{array}$ & 18 & 37,5 \\
$\begin{array}{l}\text { Berhenti } \\
\text { menggunakan }\end{array}$ & 30 & 62,5 \\
\hline Total & $\mathbf{4 8}$ & $\mathbf{1 0 0}$ \\
\hline
\end{tabular}

beberapa sebab penggunaan trihexyphenidyl dapat dilihat pada Tabel 7 .

Tabel 7 menjelaskan bahwa sebagian besar remaja menggunakan trihexyphenidyl karena orang tua/pengasuh kurang peduli terhadap remaja. Jika dilakukan uji statistik pada beberapa sebab penggunaan trihexyphenidyl menurut lingkungan keluarga didapat hasil ada hubungan antara konsumsi alkohol pada anggota keluarga dengan penggunaan trihexyphenidyl pada remaja.

Dari beberapa sebab tersebut maka dikategorikan menjadi kategori mendukung menggunakan trihexyphenidyl (skor 4-8) dan tidak mendukung menggunakan trihexyphenidyl (skor 0-3). Penentuan skor diperoleh dari penjumlahan dari keseluruhan pertanyaan dengan skor 1 jika menjawab iya dan 0 jika menjawab tidak.

Hasil penelitian menunjukkan bahwa sebesar 56,3 persen responden mendukung menggunakan trihexyphenidyl. Gambaran penggunaan trihexyphenidyl menurut lingkungan keluarga dapat dilihat pada Tabel 8.

Tabel 7. Gambaran Beberapa Sebab Penggunaan Trihexyphenidyl pada Remaja menurut Faktor Lingkungan Keluarga

\begin{tabular}{lcc}
\hline \multicolumn{1}{c}{ Sebab } & Ya & Tidak \\
\hline Orang tua lebih sering di luar rumah & $31(64,6 \%)$ & $17(35,4 \%)$ \\
Orang tua sering bertengkar & $22(45,8 \%)$ & $26(54,2 \%)$ \\
Tidak pernah berdiskusi dengan keluarga & $19(39,6 \%)$ & $29(60,4 \%)$ \\
Tidak dekat dengan keluarga & $27(56,3 \%)$ & $21(43,8 \%)$ \\
Orang tua keras & $26(54,2 \%)$ & $22(45,8 \%)$ \\
Orang tua tidak peduli & $35(72,9 \%)$ & $13(27,1 \%)$ \\
Ada anggota keluarga konsumsi alkohol & $24(50,0 \%)$ & $24(50,0 \%)$ \\
Anggota keluarga ada yang pakai narkoba & $10(20,8 \%)$ & $38(79,2 \%)$ \\
\hline
\end{tabular}


Tabel 8. Gambaran Penggunaan Trihexyphenidyl pada Remaja menurut Faktor Lingkungan Keluarga di BNN Kota Surabaya

\begin{tabular}{lccc}
\hline \multirow{2}{*}{ Faktor keluarga } & \multicolumn{2}{c}{ Penggunaan Trihexyphenidyl } & \multirow{2}{*}{ Total } \\
\cline { 2 - 3 } & Masih menggunakan & Berhenti Menggunakan & \\
\hline Mendukung & $6(28,6 \%)$ & $15(71,4 \%)$ & $25(100 \%)$ \\
Tidak mendukung & $12(44,4 \%)$ & $15(55,8 \%)$ & $23(100 \%)$ \\
\hline
\end{tabular}

Tabel 9. Gambaran Sebab Penggunaan Trihexyphenidyl Pada Remaja di BNN Kota Surabaya

\begin{tabular}{lcc}
\hline Sebab & Ya & Tidak \\
\hline Sekolah dekat dengan tempat hiburan & $22(48,3 \%)$ & $26(54,3 \%)$ \\
Ada teman sekolah menggunakan trihexyphenidyl & $19(36,9 \%)$ & $29(60,4 \%)$ \\
Sering dihukum guru & $18(37,5 \%)$ & $30(62,5 \%)$ \\
Tidak pernah ikut kegiatan sekolah & $16(33,3 \%)$ & $32(66,7 \%)$ \\
Tidak menjadi pengurus kelas & $22(45,8 \%)$ & $26(54,2 \%)$ \\
Tidak menjadi pengurus OSIS & $35(72,9 \%)$ & $13(27,1 \%)$ \\
\hline
\end{tabular}

Tabel 8 menginformasikan bahwa responden dengan lingkungan keluarga mendukung menggunakan trihexyphenidyl sebanyak 71,4 persen berhenti menggunakan trihexyphenidyl. Sedangkan lingkungan keluarga yang tidak mendukung sebesar 55,8 persen berhenti menggunakan trihexyphenidyl.

Hasil analisis dengan menggunakan chi square diperoleh nilai $\chi^{2}$ (continuity corection) sebesar 0,683 dengan nilai signifikansi sebesar 0,409. Jika menggunakan $\alpha$ sebesar 5 persen maka dapat disimpulkan bahwa tidak terdapat hubungan antara faktor lingkungan keluarga dengan penggunaan trihexyphenidyl pada remaja.

\section{Faktor Lingkungan Sekolah}

Faktor lingkungan sekolah dapat dilihat dari beberapa pernyataan seputar penyebab penggunaan trihexyphenidyl pada remaja. Penyebab remaja terbesar menggunakan trihexyphenidyl adalah karena remaja tidak sedang menjadi pengurus OSIS. Selain itu sebesar 43,8 persen keberadaan sekolah berada dekat dengan tempat hiburan. Jika dilakukan uji chi square pada beberapa sebab penggunaan trihexyphenidyl pada remaja terdapat hubungan antara teman sekolah yang menggunakan trihexyphenidyl dengan penggunaan trihexyphenidyl pada remaja.
Penyebab penggunaan remaja menggunakan trihexyphenidyl menurut faktor lingkungan sekolah dapat dikategorikan menjadi kategori mendukung menggunakan trihexyphenidyl dan tidak mendukung menggunakan trihexyphenidyl. Sekolah yang tidak mendukung menggunakan trihexyphenidyl dapat dilihat dari skor jawaban responden dengan skor 0-2 sedangkan sekolah yang mendukung menggunakan trihexyphenidyl mempunyai skor 3-6. Skor diperoleh dari penjumlahan dari seluruh pertanyaan dengan skor 1 untuk jawaban ya dan 0 untuk jawaban tidak.

Hasil penelitian menunjukkan sebesar 70,8 persen remaja berada pada lingkungan sekolah yang tidak mendukung menggunakan trihexyphenidyl. Pernyataan tentang sebab penggunaan trihexyphenidyl pada remaja dapat dilihat lebih rinci pada Tabel 9.

Hasil analisis menggunakan uji chi square didapat nilai $\chi^{2}$ (continuity corection) sebesar 0,672 dengan nilai signifikansi sebesar 0,412 . Jika menggunakan $\alpha$ sebesar 5\% maka dapat disimpulkan tidak ada hubungan antara faktor lingkungan sekolah dengan penggunaan trihexyphenidyl pada remaja.

\section{Teman Sebaya}

Faktor teman sebaya dapat dilihat melalui beberapa pertanyaan tentang sebab teman sebaya yang menyebabkan remaja menggunakan trihexyphenidyl. 
Tabel 10. Gambaran Beberapa Sebab Penggunaan Trihexyphenidyl pada Remaja menurut Faktor Teman Sebaya

\begin{tabular}{lcc}
\hline Sebab & Ya & Tidak \\
\hline Sering berkumpul dengan teman & $33(68,8 \%)$ & $15(31,2 \%)$ \\
Masuk dalam anggota geng & $2654,2 \%)$ & $22(45,8 \%)$ \\
Berkumpul dengan teman saat pulang sekolah & $28(58,3 \%)$ & $20(41,7 \%)$ \\
Mengungkapkan masalah dengan sesama pengguna trihexyphenidyl & $28(58,3 \%)$ & $20(41,7 \%)$ \\
Teman satu genk pengguna trihexyphenidyl & $29(60,4 \%)$ & $19(39,6 \%)$ \\
Sering mengonsumsi trihexyphenidyl dengan teman & $28(58,3 \%)$ & $20(41,7 \%)$ \\
Sering ditawari oleh teman & $25(52,2 \%)$ & $23(47,9 \%)$ \\
Dipaksa oleh teman & $25(52,2 \%)$ & $23(47,9 \%)$ \\
Dikucilkan teman & $2756,3 \%)$ & $21(43,8 \%)$ \\
\hline
\end{tabular}

Tabel 10 menunjukkan bahwa sebesar 68,8 persen responden mengaku lebih sering menghabiskan waktu dengan teman dari pada keluarga. Selain itu karena paksaan teman dan tawaran dari teman juga menjadi penyebab penggunaan trihexyphenidyl pada remaja. Teman sebaya yang tidak mendukung menggunakan trihexyphenidyl dapat dilihat dari skor jawaban responden dengan skor 0-4 sedangkan teman sebaya yang mendukung menggunakan trihexyphenidyl mempunyai skor 5-9. Skor diperoleh dari penjumlahan dari seluruh pertanyaan dengan skor 1 untuk jawaban ya dan 0 untuk jawaban tidak.

Beberapa sebab tersebut dikategorikan menjadi teman sebaya yang mendukung menggunakan trihexyphenidyl dan teman sebaya yang tidak mendukung menggunakan trihexyphenidyl.

Responden yang mendapat dukungan dari teman sebaya menggunakan trihexyphenidyl sebesar 56,3 persen. Beberapa sebab tersebut dapat dilihat lebih rinci pada tabel 10 .

Hasil penelitian juga menjelaskan sebesar 55,6 persen responden yang mendapat dukungan dari teman sebaya telah berhenti menggunakan trihexyphenidyl. Sedangkan pada teman sebaya yang tidak mendukung menggunakan trihexyphenidyl sebanyak 71,4 persen telah berhenti menggunakan obat tersebut. Secara lebih rinci dapat dilihat pada Tabel 11.

Hubungan antara faktor lingkungan teman sebaya dengan penggunaan trihexyphenidyl pada remaja dapat diketahui dengan menggunakan uji chi square. Hasil uji tersebut didapat hasil nilai $\chi^{2}$ (continuity corection) sebesar 0,683 dengan nilai signifikansi sebesar 0,409. Jika menggunakan $\alpha$ sebesar 5 persen maka dapat disimpulkan tidak ada hubungan antara teman sebaya dengan penggunaan trihexyphenidyl pada remaja

\section{PEMBAHASAN}

\section{Karakteristik}

Hasil penelitian yang dilakukan di BNN Kota Surabaya menunjukkan bahwa dari 48 responden lebih dari separuhnya (52,1 persen) berusia antara 12-15 tahun.

Menurut pendapat Willis (2015), usia remaja merupakan perubahan dari masa anakanak menjadi dewasa. Pada usia tersebut remaja masih beradaptasi dengan lingkungan sekitar agar dapat diakui oleh lingkungan sekitarnya. Lingkungan sekitar mengharapkan remaja yang bertanggung jawab seperti orang dewasa. Salah satunya adalah melakukan penyalahgunaan obat seperti yang dilakukan oleh kebanyakan orang dewasa. Perubahan tersebut akan membuat remaja yang tidak menemukan identitasnya menjadi bingung, sehingga remaja akan mengalami masalah-masalah baik itu dengan orang tua, teman, maupun sekolahnya.

Berdasarkan jenis kelamin didapat hasil bahwa sebagian besar remaja adalah berjenis kelamin laki-laki. Remaja yang berjenis kelamin laki-laki cenderung mengalami perubahan perilaku yang negatif. Hai ini disebabkan karena 
Tabel 11. Gambaran Penggunaan Trihexyphenidyl menurut Teman Sebaya

\begin{tabular}{lccc}
\hline \multirow{2}{*}{ Teman Sebaya } & \multicolumn{2}{c}{ Penggunaan Trihexyphenidyl } & \multirow{2}{*}{ Total } \\
\cline { 2 - 3 } & Masih Menggunakan & Berhenti & \\
\hline Mendukung & $12(44,4 \%)$ & $15(55,6 \%)$ & $27(100 \%)$ \\
Tidak mendukung & $6(28,6 \%)$ & $15(71,4 \%)$ & $21(100 \%)$ \\
\hline
\end{tabular}

laki-laki dianggap lebih mandiri oleh orang tua dari pada perempuan, sehingga lebih bebas untuk berinteraksi dengan lingkungan luar.

Najmudin (2007), berpendapat bahwa laki-laki maupun perempuan memiliki masalah yang sama seperti perubahan fisik, emosi, krisis identitas, dan beberapa konflik yang terjadi dengan lingkungan sekitar. Jika remaja tidak dapat mengendalikan tekanan yang dihadapinya, maka remaja akan cenderung memilih untuk mengambil jalan pintas meskipun banyak terjadi kesalahan.

Hasil penelitian ini juga menginformasikan bahwa paling banyak remaja sedang duduk di bangku SMP. Namun jumlah tersebut tidak mempunyai selisih yang banyak dengan responden yang duduk di bangku SMA. Bahkan ada juga responden yang sedang menjalani pendidikan di perguruan tinggi. Hal ini berarti penyebaran atau penggunaan narkoba saat ini tidak mengenal tingkat pendidikan atau bisa dikatakan telah digunakan oleh siapa saja.

Berdasarkan jenis pekerjaan orang tua, kebanyakan remaja yang menggunakan trihexyphenidyl mempunyai orang tua yang bekerja sebagai swasta. Namun ada juga yang bekerja sebagai Pegawai Negeri Sipil (PNS). Hal ini menunjukkan bahwa jenis pekerjaan orang tua yang memadai tidak menjamin remaja atau anaknya tidak menggunakan trihexyphenidyl.

Berdasarkan lama penggunaan trihexyphenidyl didapat bahwa rata-rata penggunaan trihexyphenidyl pada remaja adalah selama 16,4 bulan. Penggunaan obat tersebut paling cepat selama 5 bulan dan paling lama selama 48 bulan atau 4 tahun. Hasil ini menunjukkan bahwa lama penggunaan trihexyphenidyl pada remaja bervariasi.

Berdasarkan status penggunaan trihexyphenidyl saat ini pada remaja didapat sebesar 62,5 persen sudah berhenti menggunakan trihexyphenidyl. Hal ini berarti tingkat keberhasilan yang dicapai oleh BNN Kota Surabaya sudah baik jika dibandingkan dengan kota Malang yang hanya mencapai 30 persen saja y(Singgih, 2013).

Peningkatan keberhasilan rehabilitasi di BNN Kota Surabaya harus lebih ditingkatkan lagi agar angka keberhasilan meningkat sehingga banyak pengguna narkoba berhenti menggunakan obat tersebut.

\section{Hubungan Faktor Lingkungan Keluarga dengan Penggunaan Trihexyphenidyl pada Remaja}

Hasil uji statistik pada penelitian ini adalah tidak ada hubungan anatara faktor lingkungan keluarga dengan penggunaan trihexyphenidyl pada remaja di BNN Kota Surabaya. Hal ini tidak sesuai dengan pendapat Najmudin (2007) dan Sugiyono (2008).

Najmudin (2007), mengemukakan bahwa faktor lingkungan keluarga dapat mempengaruhi penyalahgunaan obat berbahaya. Lingkungan keluarga tersebut dapat dilihat dari kurangnya kontrol keluarga dan keadaan keluarga yang tidak harmonis. Remaja yang tidak mendapatkan perhatian dari orang tua atau pengasuh akan merasa bahwa dirinya tidak diperlukan lagi oleh keluarga, sehingga banyak remaja yang melakukan penyimpangan perilaku untuk mendapatkan perhatian keluarga.

Selain itu Sugiyono (2008), berpendapat bahwa penerapan disiplin dan tanggung jawab yang diberikan oleh remaja akan membuat remaja untuk berpikir lebih dalam apabila melakukan hal-hal negatif

Namun, jika dilakukan uji statistik antara beberapa penyebab penggunaan trihexyphenidyl dengan penggunaan trihexyphenidyl pada remaja terdapat hubungan pada salah satu sebab. Sebab tersebut adalah penggunaan alkohol di salah satu anggota keluarga. Adapun sebab lain remaja yang masih menggunakan trihexyphenidyl saat ini adalah karena remaja beranggapan obat tersebut 
banyak digunakan oleh kalangan remaja dan jika menggunakannya akan menjadi remaja yang gaul.

Penelitian yang dilakukan pada remaja di BNN Kota Surabaya menginformasikan bahwa remaja dengan faktor lingkungan keluarga yang mendukung menggunakan trihexyphenidyl sebagian besar telah berhenti menggunakan trihexyphenidyl, Hal ini disebabkan karena adanya faktor individu seperti keinginan remaja untuk berhenti menggunakan trihexyphenidyl. Namun tidak sedikit juga yang masih menggunakan trihexyphenidyl.

Beberapa hasil penelitian ini dapat disimpulkan bahwa remaja dengan faktor lingkungan keluarga mendukung menggunakan trihexyphenidyl tidak selalu menggunakan obat tersebut secara terus menurus meskipun masih ada remaja yang menggunakan trihexyphenidyl. Meskipun secara keseluruhan faktor keluarga tidak berhubungan dengan penggunaan trihexyphenidyl, tetapi salah satu penyebab berhubungan dengan penggunaan trihexyphenidyl.

\section{Hubungan Lingkungan Sekolah dengan Penggunaan Trihexyphenidyl pada Remaja}

Analisis penelitian pada faktor lingkungan sekolah diperoleh tidak ada hubungan antara lingkungan sekolah dengan penggunaan trihexyphenidyl pada remaja di BNN Kota Surabaya. Jika dianalisis beberapa sebab remaja menggunakan obat tersebut terdapat hubungan antara teman sekolah yang menggunakan trihexyphenidyl dengan penggunaan trihexyphenidyl pada remaja.

Hasil penelitian tersebut sesuai dengan pendapat Razak (2006), yang berpendapat bahwa remaja yang berada di sekolah merasa meremehkan peraturan-peraturan yang ada di sekolahnya menyebabkan penggunaan obat berbahaya pada remaja. Lokasi sekolah yang dekat dengan tempat hiburan ditambah dengan salah satu siswa menggunakan obat berbahaya dapat memicu remaja turut menggunakan obat berbahaya.

Penelitian yang dilakukan di BNN Kota Surabaya menghasilkan bahwa kebanyakan remaja yang menggunakan trihexyphenidyl dikarenakan oleh kurang aktifnya remaja dalam kegiatan atau organisasi sekolah. Selain itu kurangnya disiplin sekolah juga dapat memicu remaja menggunakan trihexyphenidyl. Namun penyebab utama penggunaan trihexyphenidyl berdasarkan lingkungan sekolah adalah adanya teman satu sekolah yang juga menggunakan obat tersebut.

Berdasarkan hasil tersebut diharapkan bahwa sekolah lebih menerapkan disiplin kepada siswanya. Sehingga murid akan merasa jera dengan hukuman yang diberikan oleh sekolah. Selain itu pengguna narkoba oleh salah satu murid harus segera dilakukan rehabilitasi agar tidak menyebabkan lebih banyaknya penggunaan narkoba di wilayah sekolah.

\section{Hubungan Teman Sebaya dengan Penggunaan Trihexyphenidyl pada Remaja}

Tekanan atau ancaman teman sebaya dapat menyebabkan remaja melakukan penyalahgunaan obat atau narkoba. Remaja selalu beranggapan bahwa teman atau sahabat adalah seseorang yang paling mengerti atas dirinya. Remaja akan melakukan berbagai cara untuk dapat diterima oleh lingkungan teman sebayanya. Perasaan cemas pada remaja akan timbul jika lingkungan menolaknya. Salah satunya adalah penggunaan obat berbahaya yang biasa dilakukan oleh satu kelompok tertentu (Martono, 2008).

Gunawan (2006), juga berpendapat bahwa remaja akan mengidentifikasikan dirinya dengan kelompok agar bisa diterima dalam kelompok tersebut. Tekanan yang diberikan oleh teman sebaya kadang bersifat positif ataupun negatif. Namun, pada umumnya remaja akan terlibat dalam perilaku yang negatif.

Hasil analisis penelitian ini menunjukkan bahwa tidak ada hubungan antara teman sebaya dengan penggunaan trihexyphenidyl. Hasil ini tidak sesuai dengan pendapat Martono (2008), dan Gunawan (2006).

Remaja yang melakukan rawat jalan di BNN Kota Surabaya mengemukakan bahwa remaja tersebut menggunakan trihexyphenidyl karena diancam atau dipaksa oleh teman geng atau kelompoknya. Selain itu ada juga yang disebabkan oleh tawaran dari teman kelompok akibat seringnya berkumpul dengan teman sesama pengguna trihexyphenidyl. Menurut status penggunaan trihexyphenidyl saat ini, banyak 
remaja yang sudah tidak lagi menggunakan obat tersebut dalam 1 bulan terakhir meskipun mendapat dukungan dari teman sebayanya.

Penggunaan trihexyphenidyl pada remaja tidak hanya disebabkan oleh faktor teman sebaya. Hal ini dapat dilihat dari ketidaksesuaian penelitian yang menyebutkan bahwa remaja dengan lingkungan teman sebaya yang mendukung menggunakan trihexyphenidyl tidak mempunyai selisih yang besar dalam status penggunaannya. Penggunaan obat tersebut dimungkinkan oleh sebab lain seperti adanya konflik yang terjadi dengan teman sebayanya. Pernyataan tersebut sesuai dengan pendapat Sarlito (2006), yang menjelaskan bahwa konflik antar teman sebaya dapat memicu remaja untuk melakukan hal-hal yang negatif.

\section{SIMPULAN DAN SARAN}

\section{Simpulan}

Sebesar 52,1 persen pengguna trihexyphenidyl berusia 12-15 tahun dan 66,7 persen berjenis kelamin laki-laki. Tingkat pendidikan remaja sebesar 50 persen adalah SMP. Sebagian besar orang tua remaja bekerja sebagai pegawai swasta. Sebesar 54,2 persen remaja menggunakan trihexyphenidyl dalam waktu 1-3 tahun dan 62,5 persen remaja telah berhenti menggunakan trihexyphenidyl.

Tidak ada hubungan antara faktor lingkungan dengan penggunaan trihexyphenidyl pada remaja di BNN Kota Surabaya.

Ada hubungan antara konsumsi alkohol pada anggota keluarga dengan penggunaan trihexyphenidyl di BNN Kota Surabaya

Ada hubungan antara penggunaan trihexyphenidyl di tempat sekolah dengan penggunaan trihexyphenidyl di BNN Kota Surabaya.

\section{Saran}

Remaja pengguna trihexyphenidyl mengetahui lebih dalam tentang dampak penggunaan narkoba atau obat berbahaya, sehingga tidak terulang menggunakannya lagi.

BNN Kota Surabaya hendaknya memberikan penyuluhan bagi sekolah-sekolah ataupun masyarakat lain tentang bahaya penyalahgunaan obat ataupun narkoba dan bagaimana cara mencegahnya.

Orang tua lebih mengawasi dan lebih perhatian pada remaja terkait pergaulan remaja saat ini

\section{DAFTAR PUSTAKA}

Amriel, R. I. 2007. Psikologi Kaum Muda Pengguna Narkoba. Jakarta: Salemba

Chomaria, N. 2008. Aku Sudah Gede. Solo: Samudera

Gunawan, W. 2006. Keren Tanpa Narkoba. Jakarta: PT.Grasindo

Kamienski, M., dan James. 2006. Farmakologi DeMYSTiFieD. Yogyakarta: Rapha Publishing

Najmudin, H. 2007. Memahami dan Membimbing Remaja Nakal. Kuala Lumpur: PTS Profesional Publishing

Martono, L. H dan Satya. J. 2008. Peran Orang Tua Dalam Mencegah dan Menanggulangi Penyalahgunaan Narkoba. Jakarta: Balai Pustaka

Razak, A dan Sayuti. 2006. Remaja dan Bahaya Narkoba. Jakarta: Prenada

Riza, I. P. 2016. Skripsi Beberapa Faktor yang Berhubungan Dengan Penggunaan Trihexyphenidyl Pada Remaja. Surabaya: Universitas Airlangga

Sarlito, W. 2006. Psikologi Remaja. Jakarta: Raja Grafindo Persada

Singgih. 2013. Pelaksanaan Pendidikan Moral Pada Peserta Rehabilitasi Pecandu Narkoba di Panti Rehabilitasi Narkoba Pondok Pemulihan Daulos Kota Batu. Vol.2 No.1

Willis, S. 2015 .Berbagai Masalah yang Dihadapi Siswa dan Solusinya. Bandung: Alfabeta. 